\title{
PENGARUH PROMOSI, KUALITAS PRODUK DAN CITRA MEREK TERHADAP KEPUASAN KONSUMEN PRODUK SUSU INDOMILK DI KECAMATAN WONOKROMO SURABAYA
}

\author{
Rendra Alfian Ardiansyah ${ }^{1}$, Tony Susilo Wibowo ${ }^{2}$ \\ Universitas PGRI AdiBuana Surabaya \\ rendraardiansyah456@gmail.com
}

\begin{abstract}
ABSTRAK
Kepuasan konsumen terjadi dikarenakan faktor promosi dan kualitas produk. promosi yang semakin terus menerus dilakukan akan membuat konsumen semakin lebih mengenal produk tersebut. Kualitas produk juga menjadi pendorong bagi penciptaan rasa puas konsumen. Faktor citra merek juga menjadi hal yang diperhatikan konsumen sebelum membeli produk. pada umumnya produk dengan citra merek terkenal akan dipilih oleh konsumen. Hal ini dikarenakan konsumen berfikir produk dengan merek yang terkenal bisa memuaskan konsumen. Konsumen produk susu indomilk di kecamatan Wonokromo, Surabaya dijadikan populasi dan diambil sampel 74 responden. Purposive sampling dijadkan sebagai teknik pengambilan sampel. Kuesioner disebar dan hasil jawaban responden dianalisis data dengan analisis regresi linier berganda. Ditemukan hasil promosi, kualitas produk dan citra merek memiliki pengaruh pada kepuasan konsumen. Ditemukan juga hasil lain promosi, kualitas produk dan citra merek memiliki pengaruh secara simultan pada kepuasan konsumen produk susu indomilk di Surabaya.
\end{abstract}

Kata kunci : Promosi, Kualitas Produk, Citra Merek, Kepuasan Konsumen

\section{ABSTRACT}

Consumer satisfaction occurs due to promotion factors and product quality. promotions that are increasingly carried out will make consumers increasingly more familiar with these products. Product quality is also a driving force for creating consumer satisfaction. Brand image factors are also things that consumers pay attention before buying products. in general, products with a well-known brand image will be chosen by consumers. This is because consumers think products with well-known brands can satisfy consumers. Consumers of indomilk milk products in Wonokromo sub-district, Surabaya are made into a population and 74 respondents are sampled. Purposive sampling is used as a sampling technique. Questionnaires were distributed and the results of respondents' answers were analyzed by data with multiple linear regression analysis. Found the results of promotions, product quality and brand image have an influence on customer satisfaction. Other results of the promotion were also found, product quality and brand image have a simultaneous influence on consumer satisfaction of indomilk milk products in Surabaya.

Keywords: Promotion, Product Quality, Brand Image, Consumer Satisfaction 


\section{PENDAHULUAN}

\section{Latar Belakang}

Banyaknya perusahaan yang didirikan khususnya di Indonesia akan membuat persaingan semakin seru. Banyak perusahaan didirikan khususnya dibidang minuman. Salah satunya PT Indolakto.

Perusahaan yang dibawah naungan PT. Indofood Nutrition ini memiliki produk minuman khususnya susu dengan merek indomilk.

Indomilk sendiri menjadi merek yang taka sing lagi bagi kebanyakan konsumen. Hal ini dikarenakan perusahaan selalu mempromosikan produk ke konsumen. Dengan promosi secara terus-menerus akan menjadikan produk tersebut semakin dikenal masyarakat. Selain itu kualitas produk juga dikenal memiliki nilai gizi dan mutu yang baik bagi tubuh sehingga konsumen saat mengkonsumsinya akan merasakan kepuasan karena kebaikan gizi yang dimiliki produk tersebut. Dengan semakin dikenalnya produk indomilk dikalangan konsumen akan membawa suatu persepsi mengenai citra merek produk tersebut. Konsumen menganggap produk indomilk memiliki manfaat yang baik bagi konsumen. Sehingga konsumen yang sudah mengkonsumsi akan merekomendasikan kekonsumen lain juga. Dengan ini akan semakin menciptakan rasa puas dari konsumen lainnya.

Dari latar belakang yang dipaparkan diatas akan diambil rumusan masalah yaitu:

1. Apakah promosi memiliki pengaruh pada kepuasan konsumen produk susu indomilk di Surabaya?.

2. Apakah kualitas produk memiliki pengaruh pada kepuasan konsumen produk susu indomilk di Surabaya?.

3. Apakah citra merek memiliki pengaruh pada kepuasan konsumen produk susu indomilk di Surabaya?.

4. Apakah promosi, kualitas produk dan citra merek memiliki pengaruh secara simultan pada kepuasan konsumen produk susu indomilk di Surabaya?.

\section{TINJAUAN PUSTAKA \\ Landasan Teori}

\section{Promosi}

Promosi diartikan sebagai perluasan lini oleh perusahaan. Perushaan akan mempromosika produknya agar semakin dikenal masyarakat luas.

Tjiptono dan Chandra, 2012 indikator promosi yaitu:

1. Produk yang dipromosikan ke konsumen

Promosi suatu produk dapat memperluas pasar dan meningkatkan penjualan.

2. Promosi di penjuru tempat atau lokasi

Semakin banyak tempat yang ditarget dan dituju akan semakin meningkat penjualan produk.

3. Promosi pembayaran

Dengan semakin banyaknya metode pembayaran semakin membuat mudah konsumen dalam bertransaksi.

\section{Kualitas Produk}

Kualitas produk diartikan ebagai suatu syarat yang harus dimiliki perusahaan dalam menciptkan produk. kualitas produk harus sesuai kebutuhan dan keinginan konsumen.

Tjiptono, 2008 Hal 25-26 Indikatornya yaitu:

1. Kinerja produk

Produk yang baik akan memiliki kinerja dalam pemenuhan kebutuhan konsumen.

2. Ketahanan

Daya tahan produk akan menjadi keunggulan produk. produk yang tahan lama dan tanpa pengawet akan 
menjadikan produk tersebut memiliki kualitas terbaik bagi konsumen.

3. Spesifikasi yang sesuai

Produk harus memiliki spesifikasi yang dibutuhkan pasar. Konsumen akan memiliki spesifikasi berbeda dalam memilih produk.

4. Fitur

Banyaknya fitur yang dimiliki produk akan semakin berkualitas produk tersebut.

5. Kehandalan

Produk harus handal dan memberikan manfaat bagi konsumen. Handal berarti produk mampu memenuhi kebutuhan konsumen.

6. Kualitas yang mengesankan

Penciptaan rasa kesan atau kagum oleh konsumen pada kualitas produk akan membawa konsumen tersebut melakukan pembelian ulang pada produk yang sama.

\section{Citra Merek}

Citra merek diartikan sebagai sebuah pendorong konsumen untuk membeli produk. citra merek produk yang baik akan dicari dan dibeli oleh konsumen. Mohammad, (2010:61) indikator citra merek yaitu:

1. Citra produsen

Produsen atau penjual yang memiliki pandangan yang jujur dan baik akan menjadikan merek produk yang dijualnya tersebut ikut menjadi baik juga.

2. Citra pelanggan

Konsumen yang merekomendasikan merek produk tertentu ke konsumen lain dan menginformasikan kalau produk tersebut membawa manfaat bagi konsumen akan membuat citra merek produk tersebut naik.

3. Citra suatu produk

Produk yang memberi manfaat dan memenuhi keinginan konsumen akan dianggap memiliki citra produk yang baik.

\section{Kepuasan konsumen(Y)}

Kepuasan konsumen diartikan sebagai pengekspresian konsumen akan manfaat yang diberikan produk. Misalnya produk tersebut memberi kenikamatan, konsumen akan puas dan sebaliknya.

Tjipto, 2014 indikator kepuasan konsumen yaitu:

1. Harapan yang sesuai

Harapan konsumen akan tercapai kalau sebuah produk akan membawa dampak positif bagi konsumen tersebut.

2. Adanya minat untuk kunjungan kembali

Konsumen yang mengulangi pembelian pada produk yang sama bisa dikatakan konsumen tersebut puas dengan produk tersebut.

3. Bersedia merekomendasikan

Setelah konsumen merasakan kepuasaan konsumen tersebut akan merekomendasikan produk yang dibelinya kekonsumen lain agar membelinya juga.

\section{Kerangka Konseptual}

Berikut kerangka konseptual akan dipaparkan dibawah: 


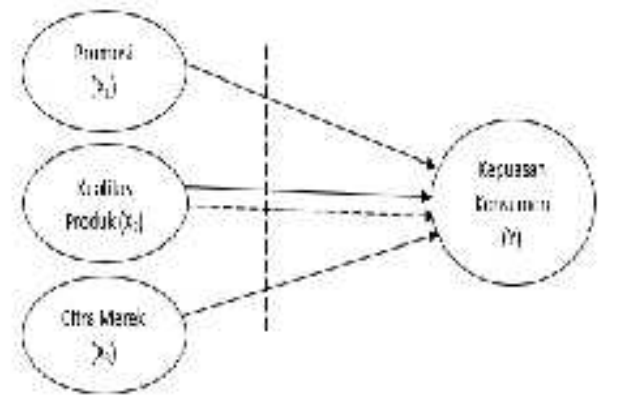

Gambar 1. kerangka konseptual

\section{Hipotesis}

H1 : Variabel (X1) memiliki pengaruh pada variabel (Y) produk susu indomilk di Surabaya.

$\mathrm{H} 2$ : Variabel (X2) memiliki pengaruh pada varabel (Y) produk susu indomilk di Surabaya.

H3 : Variabel (X3) memiliki pengaruh pada variabel (Y) produk susu indomilk di Surabaya

H4 : Variabel (X1), (X2), dan (X3) memiliki pengaruh pada variabel (Y) produk susu indomilk di Surabaya.

\section{METODE PENELITIAN}

Populasi dan Sampel

Konsumen produk susu indomilk di Kecamatan Wonokromo, Surabaya dijadikan populasi dan diambil sampel 74 responden. Purposive sampling dijadikan sebagai teknik pengambilan sampel. Kuesioner disebar ke responden dan hasil jawaban responden akan dianalisis data dengan analisis regresi linier berganda.

\section{HASIL}

\section{(Uji Validitas)}

Berikut validity test akan dipaparkan sebagai berikut:

Tabel 1.

(Uji Validitas)

\begin{tabular}{|c|c|c|}
\hline$(\mathbf{V})$ & $\mathbf{R}_{\text {hitung }}$ & $\mathbf{R}_{\text {tabel }}$ \\
\hline \multirow{2}{*}{$\mathrm{X}_{1}$} & .875 & \multirow{2}{*}{$>0.3$} \\
\cline { 2 - 2 } & .853 & \\
\hline
\end{tabular}

\begin{tabular}{|c|c|c|}
\hline & .920 & \\
\hline & .889 & \\
\hline & .905 & \\
\hline & .864 & \\
\hline \multirow{6}{*}{$\mathrm{X}_{2}$} & .908 & \multirow{6}{*}{$>0.3$} \\
\hline & .817 & \\
\hline & .839 & \\
\hline & .834 & \\
\hline & .776 & \\
\hline & .661 & \\
\hline \multirow{6}{*}{$X_{3}$} & .856 & \multirow{6}{*}{$>0.3$} \\
\hline & .880 & \\
\hline & .893 & \\
\hline & .820 & \\
\hline & .823 & \\
\hline & .847 & \\
\hline \multirow{6}{*}{$\mathrm{Y}$} & .857 & \multirow{6}{*}{$>0.3$} \\
\hline & .826 & \\
\hline & .825 & \\
\hline & .845 & \\
\hline & .790 & \\
\hline & .841 & \\
\hline
\end{tabular}

Dapat dilihat diatas $R_{\text {hitung }}>$ dari $R_{\text {tabel }}$ artinya semua pernyataan pada variabel valid.

\section{(Uji Realibilitas)}

Berikut akan dipaparkan hasil uji realibilitas:

Tabel 2.

(Uji Realibilitas)

\begin{tabular}{|c|c|c|}
\hline$($ V) & $\begin{array}{c}\text { Cronbach } \\
\text { Alpha }\end{array}$ & $\begin{array}{c}\text { Nilai } \\
\text { Kritis }\end{array}$ \\
\hline$\left(\mathrm{X}_{1}\right)$ & .943 & .70 \\
\hline$\left(\mathrm{X}_{2}\right)$ & .892 & .70 \\
\hline$\left(\mathrm{X}_{3}\right)$ & .924 & .70 \\
\hline$(\mathrm{Y})$ & .910 & .70 \\
\hline
\end{tabular}

Dilihat dari tabel diatas nilai cronbach alpha >.70. artinya pernyataan pada semua variabel reliable.

\section{(Uji Normalitas)}


Berikut akan dipaparkan hasil uji normalitas:

Tabel 3.

(Uji normalitas)

\begin{tabular}{|c|c|}
\hline & $\begin{array}{c}\text { Unstandardised } \\
\text { Residual }\end{array}$ \\
\hline $\mathrm{N}$ & 74 \\
\hline Uji Statistik & .086 \\
\hline $\begin{array}{c}\text { Asymp.sig(2- } \\
\text { tailed) }\end{array}$ & $.200^{\mathrm{c}}$ \\
\hline
\end{tabular}

Apabila nilai asymp.sig.200>.05 diartikan variabel berdistribusi normal.

\section{(Uji Multikolinieritas)}

Berikut hasil uji multikolinieritas akan disajikan lewat tabel berikut:

Tabel 4.

(Uji Multikolinieritas)

\begin{tabular}{|c|c|c|}
\hline$(\mathbf{V})$ & (Tolerance) & $(\mathbf{V I F})$ \\
\hline$\left(\mathrm{X}_{1}\right)$ & .881 & 1.135 \\
\hline$\left(\mathrm{X}_{2}\right)$ & .971 & 1.030 \\
\hline$\left(\mathrm{X}_{3}\right)$ & .906 & 1.103 \\
\hline Nilai tolerance $(>.10)$ & dan $(\mathrm{VIF}<10)$.
\end{tabular}

Maka data diatas tidak terjadi multikolinieritas.

\section{(Uji Heteroskedastisitas)}

Berikut akan dipaparkan hasil uji hesteroskedastisitas:

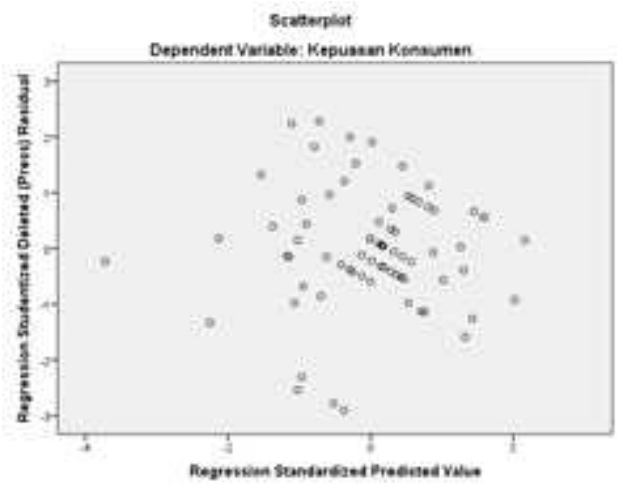

\section{Gambar 2.}

(Uji Hesteroskedastisitas)

Dilihat hasil diatas titik tersebar acak dan rata serta tidak ada bentuk pola tertentu artinya tidak terjadi heteroskedastisitas

(Uji Autokorelasi)

Berikut hasil uji autokorelasi akan disajikan lewat tabel berikut:

Tabel 6.

(Uji Autokorelasi)

\begin{tabular}{|c|}
\hline (DW) \\
\hline 2.054 \\
\hline
\end{tabular}

Nilai (DW $1.49<2.054<2.49)$ artinya tidak terjadi autokorelasi.

(Uji T)

Hasil uji t akan disajikan berikut ini: Tabel 7.

(Uji T)

\begin{tabular}{|c|c|c|}
\hline $\begin{array}{c}\text { Koefisien } \\
\text { Standar }\end{array}$ & $(\mathbf{T})$ & $(\mathbf{S i g})$ \\
\hline$\left(\mathrm{X}_{1}\right)$ & 2.696 & .009 \\
\hline$\left(\mathrm{X}_{2}\right)$ & 2.782 & .007 \\
\hline$\left(\mathrm{X}_{3}\right)$ & 3.246 & .002 \\
\hline \multicolumn{2}{|c|}{ Derhitungan diatas }
\end{tabular}

diketahui jika:

1. Variabel $\left(\mathrm{X}_{1}\right) \mathrm{t}_{\text {hitung }} 2.696$ dengan nilai sig .009. Sehingga $(.009<.05)$ artinya variabel $\mathrm{X}_{1}$ memiliki pengaruh pada variabel $\mathrm{Y}$.

2. Variabel $\left(\mathrm{X}_{2}\right)$ thitung $_{2.782}$ dengan nilai sig .007. Sehingga $(.007>.05)$ artinya variabel $\mathrm{X}_{2}$ memiliki pengaruh pada variabel $\mathrm{Y}$.

3. Variabel $\left(\mathrm{X}_{3}\right)$ thitung 3.246 dengan nilai sig .002. Sehingga $(.002<.05)$ artinya 
variabel $\mathrm{X}_{3}$ memiliki pengaruh pada variabel Y.

(Uji F)

Hasil uji f akan disajikan berikut:

Tabel 8.

(Uji F)

\begin{tabular}{|c|c|c|}
\hline (Model) & (F) & (Sig) \\
\hline Regresi & 12.340 & .000 \\
\hline \multicolumn{2}{|c|}{ Dari hasil uji f diatas nilai f $\mathrm{f}_{\text {hitung }}$} \\
\multicolumn{2}{|c|}{}
\end{tabular}

12.340 dengan nilai sig $.000<.05$ artinya variabel $\left(\mathrm{X}_{1}\right),\left(\mathrm{X}_{2}\right)$ dan $\left(\mathrm{X}_{3}\right)$ memiliki pengaruh seacara bersama-sama pada variabel Y.

\section{PEMBAHASAN}

1. Dari hasil uji t nomor 1. Hasil ini sesuai dengan penelitian dari Andreas S. Manampiring, Willem J.

A. F. Tumbuan, Rudy S. Wenas (2016).. Hasil ini membuktikan kalau jika promosi menjadi sebuah pendorong terciptanya kepuasan konsumen. Promosi yang terus dilakukan akan semakin menambah peningkatan penjualan. Disisi lain juga menciptakan rasa puas konsumen. Hal ini dikarenakan dengan promosi konsumen yang lain akan mengetahui juga keunggulan dari produk yang dipromosikan sehingga penjualan meningkat dan konsumen yang sebelumnya sudah mengkonsumsi produk tersebut merasa puas juga karena produk yang dikonsumsinya selama ini makin dikenal masyarakat.

2. Dari hasil uji t nomor 2. Hasil ini sesuai dengan penelitian dari Jessica J. Lenzun, James D.D, Massie Decky Adare (2014). Kualitas produk yang terbaik akan menjadikan pengaruh konsumen dalam menciptakan kepuasan. Kualitas yang terjamin dan selalu memberikan manfaat baik bagi tubuh akan membuat produk tersebut juga menimbulkan rasa puas didiri konsumen. Kepuasan konsumen akan suatu produk juga dapat dilihat dari fungsi produk yang mampu memenuhi kebutuhan konsumen.

3. Hasil dari uji t nomor 3. Hasil sesuai penelitian dari Christian Lasander (2013). Merek menjadi sebuah identitas produk untuk digunakan sebagai pembeda dari produk lainnya. Citra merek harus terus dibentuk oleh perusahaan karena citra merek produk yang selalu memberikan manfaat bagi konsumen akan menimbulkan rasa puas dari konsumen juga.

4. Dari hasil ujit $f$ diartikan Kepuasan pelanggan tercipta karena suatu promosi dan kualitas produk yang terus ditingkatkan serta citra merek produk yang terus dijaga dan selalu memberikan manfaat serta memberi pemenuhan kebutuhan konsumen akan menciptakan rasa puas pada produk tersebut.

\section{SIMPULAN}

1. Dari hasil uji t sebelumnya diartikan promosi secara terus menerus dilakukan oleh perusahaan akan semakin memperluas pasar dan semakin banyak konsumen terpuaskan akan hadirnya produk tersebut.

2. Pada hasil uji t yang dilakukan sebelumnya diartikan kualitas produk yang semakin terjamin mutu dan 
gizinya akan menjadikan konsumen puas akan kualitas produk tersebut.

3. Dilihat dari uji t dapat diartikan citra merek akan selalu meningkat jika perusahaan terus memuaskan konsumen. Hal ini dikarenakan konsumen yang puas, citra merek produk akan naik dan menjadi kegemaran konsumen lain juga.

4. Diliha dari hasil uji $\mathrm{f}$ diartikan kepuasan konsumen tercipta karena promosi yang dilakukan perusahaan dan kualitas produk yang selalu terjaga sampe ke tangan konsumen serta citra merek produk yang terus ditingkatkan agar konsumen lain puas mengkonsumsi produk tersebut.

\section{IMPLIKASI}

Produk susu indomilk merupakan produk dengan citra merek yang sudah dikenal kebanyakan orang. Untuk semakin memperluas pasar perlu dilakukan promosi produk agar konsumen yang ingin membeli produk tersebut juga akan merasakan kepuasan yang diberikan produk khususnya susu indomilk. Kualitas produk yang sudah dikenal memiliki mutu dan gizi yang baik bagi tubuh membuat susu indomilk memiliki cita merek sendiri dihati konsumennya. Akan tetapi perlu ditingkatkan lagi kepuasan konsumen misalnya dengan selalu melakukan inovasi rasa susu yang diinginkan konsumen dipasaran.

\section{KETERBATASAN PENELITIAN}

Responden banyak yang kuisioner tanpa memahami dan mengerti pernyataan terlebih dahulu. Waktu, biaya, dan tenaga yang terbatas menjadi kendala dalam proses pengambilan data.

\section{DAFTAR RUJUKAN}

Andreas S. Manampiring, dkk. (2016). ANALISIS PRODUK, HARGA,
LOKASI, PROMOSI TERHADAP KEPUASAN KONSUMEN PADA KARTU KREDIT PT.BANK MANDIRI TBK MANADO. Jurnal EMBA Manajemen Universitas Sam Ratulangi Manado, Vol.4 No.2 2016, Hal. 164-176.

Alma, Buchari, 2011, Manajemen Pemasaran dan Pemasraran Jasa, Alfabeta: Bandung.

Christian Lasander, (2013). CITRA MEREK, KUALITAS PRODUK, DAN PROMOSI PENGARUHNYA TERHADAP KEPUASAN KONSUMEN PADA MAKANAN TRADISIONAL. Jurnal EMBA, Vol.1 No.3 2013, Hal. 284-293.

Fandy Tjiptono. 2014. Pemasaran Jasa (Prinsip, Penerapan, Penelitian). Yogyakarta. Andi.

Ghozali, Imam. 2013. Aplikasi Analisis Multivariate dengan Program IBM SPSS19, Badan Penerbit Universitas Diponegoro, Semarang.

Jessica J.Lenzun, dkk. (2014).

PENGARUH KUALITAS PRODUK, HARGA DAN PROMOSI TERHADAP KEPUASAN PELANGGAN KARTU PRABAYAR TELKOMSEL. Jurnal EMBA, Vol.4 No.3 2014, Hal. 12371245.

Kotler, Philip \& Gerry Amstrong, (2014): Principle Of Marketing, $15^{\text {th }}$ edition. New jersey: pearson Prentice Hall.

Kotler dan Keller, 2012. Marketing Management. Global edition. Publishing as Prentice Hall.

Kotler, Philip, Kevin Lane Keller. (2012). Marketing Management, $14^{\text {th }}$ Edition United States of America:Person.

Kotler, P. Dan K.L. Keller. 2009. Manajemen Pemasaran. Edisi 12. Indeks, Jakarta Hal 103.

Manampiring, A., \& Wenas, R. (2016). Analisis Produk, Harga, Lokasi, Promosi Terhadap Konsumen Pada Kartu Kredit PT.Bank Mandiri Tbk. Manado. Jurnal Riset Ekonom, Manajemen Bisnis Dan Akuntansi, 4 (2), $164-176$ 
Tjiptono, Fandy. (2002). Strategi Pemasaran. Edisi 3, Andi: Yogyakarta.

Sugiyono. 2010. Metodologi Penelitian Pendidikan Kuantitatif, Kualitatif, dan $R \& D$. Bandung. Alfabeta.

Tjiptono, Fandy. (2002). Strategi Pemasaran. Yogyakarta: Penerbit Andi. Tjiptono, Fandy. 2008, Strategi Pemasaran, Edisi 3, Andi: Yogyakarta. 
Journal of Sustainability Business Research

ISSN : 2746 -

8607

Vol. 1 No. 1 Desember 2020 